\title{
Determinants of Fertility Desire among Women Living with HIV in the Childbearing Age Attending Antiretroviral Therapy Clinic at Jimma University Medical Center, Southwest Ethiopia: A Facility-Based Case-Control Study
}

\author{
Nigusie Shifera Aylie $\mathbb{D}^{1},{ }^{1}$ Lelisa Sena Dadi, ${ }^{2}$ Eshetu Alemayehu, \\ and Mengistu Ayenew Mekonn ${ }^{3}$ \\ ${ }^{1}$ Nursing Department, College of Health Science Mizan-Tepi Unversity, Mizan-Aman, Ethiopia \\ ${ }^{2}$ Epidemiology Department, Faculty of Public Health, Jimma University, Jimma, Ethiopia \\ ${ }^{3}$ Epidemiology Department, College of Health Science Mizan-Tepi Unversity, Mizan-Aman, Ethiopia \\ Correspondence should be addressed to Nigusie Shifera Aylie; nigusieshifera@gmail.com
}

Received 7 February 2020; Revised 23 July 2020; Accepted 31 July 2020; Published 12 August 2020

Academic Editor: Robert Gaspar

Copyright (c) 2020 Nigusie Shifera Aylie et al. This is an open access article distributed under the Creative Commons Attribution License, which permits unrestricted use, distribution, and reproduction in any medium, provided the original work is properly cited.

\begin{abstract}
Background. High fertility and aspiration to have more children are a normal phenomenon in many developing countries including Ethiopia. The desire of people living with HIV/AIDS (PLWHA) to have children can have significant public health implications. Despite the growing number of women living with HIV/AIDS, the issues of fertility and childbearing intention have not been widely studied in Ethiopia. Objective. To identify determinants of fertility desire among women living with HIV in the childbearing age attending antiretroviral therapy clinic at Jimma University Medical Center, Southwest Ethiopia. Methods. A facility-based case-control study was conducted in March 2019. Cases were women living with HIV who had fertility desire, and controls were those who had not. Data was collected using a face-to-face interview using a pretested questionnaire. The data was entered into EpiData 3.1 and exported to SPSS Version 24 for analysis. Bivariate and multivariable logistic regression analyses were used to identify candidate and independent determinants of fertility desire, respectively. Independent determinants associated with fertility desire were assessed using AORs with their corresponding 95\% CIs at $P$ value $<0.05$ cutoff point. Results. Three hundred forty-four (115 cases and 229 controls) were included into the study with a $100 \%$ response rate. Age categories 15-24 (AOR: 4.1; 95\% CI: 2.0, 8.4) and 25-34 (AOR: 2.3; 95\% CI: 1.3, 4.2) years, not using family planning (AOR: 2.3; 95\% CI: 1.4, 4.0), and having a sexual partner (AOR: 1.9; 95\% CI: 1.1, 3.2) were independent predictors of fertility desire. Conclusions. Age of women, family planning, and sexual partner were found to be the independent predictors of fertility desire among women living with HIV/AIDS. Policymakers and health care providers who are working on an ART clinic should try to consider the effects of these factors for women living with HIV while developing HIV/AIDS interventions and discussing on sexual and reproductive health issues with their clients, respectively.
\end{abstract}

\section{Introduction}

Globally, an estimated 36.7 million people were living with HIV/AIDS; over 25.5 million of them are in Africa where $76 \%$ of all HIV-positive women live in sub-Saharan Africa.
AIDS-related illnesses remain the leading cause of death among women of reproductive age (15-49 years). It is the second leading cause of death among young women aged 15-24 years globally, and the first in Africa [1]. In Ethiopia, HIV prevalence among women of the reproductive age 
(15-49 years) was $0.9 \%$ and the most affected group are those who are sexually active and economically productive falling within the 25-49 age group [2].

Women's desires for fertility can put them on danger against the preventive strategies for vertical transmission of HIV/AIDS. Worldwide, over $90 \%$ of HIV infections among young children are due to mother-to-child transmission (MTCT). In the absence of any appropriate intervention, transmission of HIV/AIDS ranges from $15 \%$ to $45 \%$. This transmission rate can be reduced to under $5 \%$ with effective interventions during the times of pregnancy, labor, delivery, and breastfeeding [3].

The UNICEF report estimated that MTCT of HIV was 9\% in Latin America and Caribbean, 15\% in Eastern Europe and Central Asia, 16\% in Middle East and Northern Africa, $18 \%$ in West and Central Africa, and $8 \%$ in East and Southern Africa [4]. In Ethiopia, a finding from systematic review showed that the pooled prevalence of MTCT of HIV was 9.93\%. Furthermore, the study also showed that almost one in every ten HIV-exposed infants became HIV positive [5]. Moreover, Ethiopia was characterized by low PMTCT service coverage. For example, Ethiopian public health institute (EPHI) reports indicated that more than 30,818 (8\%) mothers need PMTCT of HIV/AIDS that cannot be addressed in 2018 [6].

Evidence indicates that women living with HIV continue with desire of having more children at varying degrees. For example, two studies conducted in Canada [6] and Malawi [7] showed that the proportions of HIV-positive women who wanted to have children in the future were $69 \%$ and $17 \%[7,8]$, respectively. In Ethiopia, different studies indicated different levels of fertility desire among HIV-positive women. A study done in Nekemt Town [9], Tigray, [10] and Addis Ababa [11] demonstrated that the proportions of women living with HIV who had fertility desire were $42.1 \%, 45.5 \%$, and $56.2 \%$, respectively.

Studies revealed that age $[7,10,12-20]$, ethnicity $[7,10$, $13]$, education status $[9,15,18,21]$, religion $[19,21]$, residence [7], marital status [10, 20-22], wealth status [18], abortion [13], children $[12,13,20]$, parity $[7,8,12,20,23]$, sexual violence [24], sexual activity [24], child HIV status [10], sexual partner [19, 23], partner desire [9, 13, 15, 17, 25], discussion [10], family planning [8,21], family influence [20], CD4 count [10, 23], viral load [13], ART duration [10], HIV diagnosis, HIV disclosure [12], partner HIV status [9, 11], health status [22, 23], knowledge [15], effects of HIV on fertility [17], and perceived stigma [14] were among the factors associated with fertility desire.

In Ethiopia, limited studies have pointed out different factors that determine fertility desire of HIV-positive women $[9,10,12,20,22]$. However, no study has been conducted before in our study area to identify fertility desire of women living with HIV. Moreover, most of the previous studies does not assess HIV pregnancy-related knowledge and household wealth status, so this study strengthens the previous findings by addressing the above gaps.

The main aim of this study was to identify determinants of fertility desire among women living with HIV in Jimma University Medical Center, Southwest Ethiopia. So, this study had an implication for PMTCT of HIV/AIDS, the need for counseling to facilitate informed decision-making about childbearing, and the future demand for services for children born to infected women by identifying factors that determine fertility desire of women.

\section{Methods}

2.1. Study Setting, Design, and Period. An institution-based case-control study was conducted at Jimma University Medical Center (JUMC) in March 2019. Geographically, JUMC is located in Jimma City, which is $352 \mathrm{~km}$ to southwest of Addis Ababa. Currently, it is the only teaching and referral hospital in the southwestern part of the country, providing services to approximately 15,000 inpatient, 160,000 outpatient attendants, 11,000 emergency cases, and 4500 deliveries in a year. A total of $3221 \mathrm{HIV}$-positive individuals were on ART follow-up at JUMC ART clinic, of whom 1956 were females and 1775 were women in the reproductive age. Every stable client attends clinics every month, but clients with severe illness have frequent appointments within a month. The clinic provides counseling, tracing, ART treatment, and nutritional and medical treatment services.

2.2. Eligibility Criteria. All consecutively selected women living with HIV in the reproductive age (15-49) who had a follow-up in the ART clinics of Jimma University Medical Center were included in this study. Women who were pregnant, have severe mental illness, had hearing difficulties, and/or with confirmed infecundity were excluded.

\subsection{Sample Size Determination and Sampling Technique.} Sample size was estimated using two population proportion formulas for unmatched case-control study using Epi Info version 7 StatCalc function considering assumptions of $95 \%$ CI, $80 \%$ power, and a case-control ratio of $1: 2$. From a similar study conducted in Addis Ababa, health status of the women living with HIV was taken as the main predictor of outcome fertility desire. $P_{1}$ representing the proportion of cases who are exposed to very good current health status was $60 \%$, and $P_{2}$ representing the proportion of controls who are exposed to very good current health status was $44.4 \%$ [11]. Then, after considering a $10 \%$ nonresponse rate, the total sample size was estimated to be 344 (cases $=115$, controls $=229$ ). Study participants were grouped as cases if they had fertility desire and controls if they did not have fertility desire among women living with HIV on ART follow-up. The actual participants were selected through a consecutive sampling technique based on the criteria of the case definition.

\subsection{Measures and Operational Definitions}

2.4.1. Fertility Desires. It is a psychological state in which someone has the personal motivation to have a child. Those who have motivation to have more children in the future have fertility desire, and those who did not have motivation to have more children were considered not to have fertility desire during the study period [26]. 
2.4.2. Sexually Active. Women who had at least one sexual practice during the last six months before the interview were labeled as sexually active [27].

2.4.3. Good Knowledge. Those respondents who answered correctly at least $60 \%$ of the total knowledge questions are considered to have good knowledge [28].

2.4.4. Poor Knowledge. Those respondents who correctly answered less than $60 \%$ of the total knowledge's questions are considered to have poor knowledge [28].

2.4.5. Housewife. A housewife is a woman whose work is running or managing her family and does not have any other job [26].

2.4.6. Wealth Index. Households are given scores based on the number and kinds of household assets, and the scores are derived using principal component analysis (PCA) [2].

2.4.7. Sexual Violence. Sexual violence is any sexual act, attempt to obtain a sexual act, unwanted sexual comments or advances, or acts to traffic or otherwise directed against a person's sexuality using coercion, by any person regardless of their relationship to the victim, in any setting throughout their life [29].

2.4.8. Viral Load. The amount of HIV in a sample of blood. Viral load (VL) is reported as the number of HIV RNA copies per milliliter of blood. In this study, it has three categories. The first category is TND which means target not detected or the virus is not at a detectable level. The second and third categories are the detectable level which is $<20$ copies and $\geq 20$ copies HIV RNA copies per milliliter of blood, respectively [30].

2.5. Data Collection Procedures and Tools. After confirming eligibility and obtaining written informed consent, consecutively selected participants were asked to respond to an interviewer-administered questionnaire which was prepared in the local (Amharic and Affan Oromo) languages. The questionnaire assessed sociodemographic and socioeconomic characteristics, fertility desire, reproductive characteristics, clinical characteristics, and HIV pregnancy-related knowledge. Questions were adapted from previously conducted similar studies [7-25]. Medical records of HIVpositive women were reviewed to confirm HIV status and other relevant medical history, including date of HIV diagnosis, recent CD4 count, ART status, date of ART start, and viral load.

2.6. Data Management and Analysis. Data completeness was checked manually, then entered into EpiData 3.1 and exported to SPSS Version 24 for analysis. Pretest of the questionnaire was conducted in Shenen Gibe Hospital, which had similar services to the study hospital. Training was given to the data collectors and supervisors on the objective of the study, maintenance of ethical standards, and methods of data collection; hence, the data collectors were familiarized with data collection tools with respect to the study with practical exercises. Data collectors were blinded about the outcome of the study so that they did not distinguish cases and controls.

The study participants were identified/classified after data collection based on unique identification codes. Data coding and cleaning were performed by cross-checking to printout data for possible errors. Missing values and outliers were checked before analysis by running descriptive analysis. The household wealth index was computed using the PCA method by considering locally available household assets which were dummy coded. Before running the PCA, the requirements of factor analysis were checked.

The descriptive statistics were presented in frequency tables and graphs. Normality assumption was checked for age. Multicollinearity between the independent variables was checked. The association between fertility desire and each covariate was assessed first by bivariate logistic regression to identify candidate variables for the final model. Variables with $P$ value $<0.25$ were taken into multiple logistic regression analysis to identify independent predictors of fertility desire.

The backward likelihood ratio with 0.1 probability removal was used to develop the model. Goodness of fit of the final model was checked using the Hosmer-Lemeshow test of goodness of fit considering good fit at $P$ value $>0.05$, omnibus likelihood test $<0.05$, and model classification of accuracy was checked. Finally, independent predictors of fertility desire were declared at $P$ value $<0.05$ cutoff point, and strength of the association was assessed using AORs with their corresponding 95\% CIs.

2.7. Ethical Statement. The study was approved by the Research and Ethics Committee, of Jimma University Institute of Health. Then, relevant offices were communicated for their cooperation with a formal letter issued by the Research and Ethics Committee. The purpose of the study was verified briefly to the study participant, and confidentiality was assured. Finally, written consent was obtained from study participants before conducting the interview. For women, who were married and less than 18 years of age, in addition to the assent, permission of their husbands was obtained to include them in the study. But for study participants, who are less than 18 years of age, were not married, and are living independently, as there is no one to sign on behalf of the parent or guardian, only assents from the participant were obtained.

\section{Results}

3.1. Sociodemographic and Economic Characteristics. A total of 115 cases and 229 controls were included in the study with a $100 \%$ response rate. Three-fourth of the $87(75.7 \%)$ cases and majority $185(80.8 \%)$ of the controls were urban residents. Concerning the age of the study participants, the mean age of cases was $28.5 \pm 5.6 \mathrm{SD}$ and the mean age of controls was $32.7 \pm 6.5$ SD. Closely half $54(47.0 \%)$ of the cases and 101 (44.1\%) of the controls were Orthodox religion followers. Concerning marital status of the study participants, 53 (46.1\%) of the cases and nearly half 111 (48.5\%) of the controls were married. 
TABLE 1: Bivariate analysis of sociodemographic and economic characteristics of women living with HIV attending ART at Jimma University Medical Center, $2019(N=344)$.

\begin{tabular}{|c|c|c|c|c|c|}
\hline Variables & Category & $\begin{array}{c}\text { Cases }(n=115) \\
\text { No. }(\%)\end{array}$ & $\begin{array}{c}\text { Controls }(n=229) \\
\text { No. }(\%)\end{array}$ & $\operatorname{COR}(95 \% \mathrm{CI})$ & $P$ values \\
\hline \multirow{3}{*}{ Age } & $15-24$ & $38(33.1)$ & $31(13.5)$ & $5.9(3.0-11.4)$ & $0.001^{*}$ \\
\hline & $25-34$ & $55(47.8)$ & $92(40.2)$ & $2.9(1.6-5.1)$ & $0.001^{*}$ \\
\hline & $35-49$ & $22(19.1)$ & $106(46.3)$ & 1 & \multirow{4}{*}{0.27} \\
\hline \multirow{2}{*}{ Residence } & Urban & $87(75.7)$ & $185(80.8)$ & 1 & \\
\hline & Rural & $28(24.3)$ & $44(19.2)$ & $0.7(0.4-1.3)$ & \\
\hline \multirow{4}{*}{ Religion } & Orthodox & $54(47.0)$ & $101(44.1)$ & 1 & \\
\hline & Muslim & $36(31.3)$ & $77(33.6)$ & $0.9(0.5-1.5)$ & 0.610 \\
\hline & Protestant & $21(18.2)$ & $44(19.2)$ & $0.9(0.5-1.6)$ & 0.718 \\
\hline & Others & $4(3.5)$ & $7(3.1)$ & $1.1(0.3-3.1)$ & 0.918 \\
\hline \multirow{4}{*}{ Ethnicity } & Oromo & $56(48.7)$ & $116(50.7)$ & 1 & \\
\hline & Amhara & $34(29.6)$ & $56(24.4)$ & $1.2(0.7-2.1)$ & 0.399 \\
\hline & Keffa & $12(10.4)$ & $33(14.4)$ & $0.7(0.4-1.6)$ & 0.449 \\
\hline & Others & $13(11.3)$ & $24(10.5)$ & $1.1(0.5-2.4)$ & 0.762 \\
\hline \multirow{5}{*}{ Marital status } & Single & $28(24.3)$ & 45 (19.7) & 1 & \\
\hline & Married & $53(46.1)$ & $111(48.5)$ & $0.8(0.4-1.4)$ & 0.366 \\
\hline & Divorced & $11(9.6)$ & $25(10.9)$ & $0.7(0.3-1.6)$ & 0.425 \\
\hline & Widowed & $11(9.6)$ & $23(10.0)$ & $0.7(0.3-1.5)$ & 0.381 \\
\hline & Separated & $12(10.4)$ & $25(10.9)$ & $0.9(0.3-2.5)$ & 0.866 \\
\hline \multirow{5}{*}{ Educational level } & Cannot read \& write & $9(7.8)$ & $19(8.3)$ & $1.3(0.5-3.3)$ & 0.542 \\
\hline & Read \& write & $25(21.7)$ & $54(23.6)$ & $1.4(0.7-2.6)$ & 0.362 \\
\hline & Elementary & $28(24.4)$ & $61(26.6)$ & $1.3(0.7-2.6)$ & 0.335 \\
\hline & Secondary & $24(20.9)$ & 49 (21.4) & $1.4(0.6-2.5)$ & 0.463 \\
\hline & Tertiary & $29(25.2)$ & $46(20.1)$ & 1 & \\
\hline \multirow{6}{*}{ Occupation } & Housewife & $30(26.0)$ & $53(23.1)$ & 1 & \\
\hline & Unemployed & $10(8.7)$ & $28(12.2)$ & $0.6(0.3-1.5)$ & 0.288 \\
\hline & Daily labor & $13(11.3)$ & $34(14.8)$ & $0.7(0.3-1.5)$ & 0.324 \\
\hline & Merchant & $17(14.8)$ & $43(13.8)$ & $0.7(0.3-1.4)$ & 0.327 \\
\hline & Govt. employee & $31(27.0)$ & $39(17.0)$ & $1.4(0.7-2.7)$ & 0.306 \\
\hline & Private business & $14(12.2)$ & $32(14.1)$ & $0.8(0.4-1.8)$ & 0.513 \\
\hline \multirow{3}{*}{ Household wealth index } & Poor & $43(37.4)$ & $71(31.0)$ & 1 & \\
\hline & Medium & $33(28.6)$ & $84(36.7)$ & $0.6(0.4-1.1)$ & $0.125^{*}$ \\
\hline & Good & $39(33.9)$ & $74(32.3)$ & $0.9(0.5-1.5)$ & 0.615 \\
\hline
\end{tabular}

Key: $*=P$ value $<0.25 ; 1=$ reference category.

In bivariate analysis, from all sociodemographic and economic characteristics, age of the respondents and household wealth status were potential candidates for multivariable logistic regression (see Table 1).

3.2. Reproductive Characteristics. Majority of the cases 95 $(83.3 \%)$ reported to have planned to have one or two children where more than half 67 (58.3\%) of the cases wished to have children within a two-year duration. Among controls, the main reason not to have children for about 80 (34.9\%) were due to fear of mother-to-child transmission of HIV (see Figure 1).

Almost all 113 (98.2\%) of the cases and 227 (99.1\%) of the controls reported to have had sexual intercourse in their lifetime. About three-fourth $86(76.1 \%)$ of the cases and closely two-third 139 (61.2\%) of the controls were sexually active in the last 12 months preceding the study. More than half $65(57.5 \%)$ of the cases and three-fourth $(77.1 \%)$ of the controls had children. Majority of 89 (78.8\%) cases and 161 (70.9\%) controls had no history of abortion. Regarding family planning option, slightly below three-fourth of $82(72.6 \%)$ cases had not used family planning and 126 (55.5\%) controls used family planning. About two-third 75 (65.2\%) of the cases and slightly above three-fourth 177 (77.3\%) of the controls had no any history of sexual violence.

In bivariate analysis, from all reproductive characteristics, sexual activity in the last 12 months, having a sexual partner currently, lack of child, history of abortion, family 


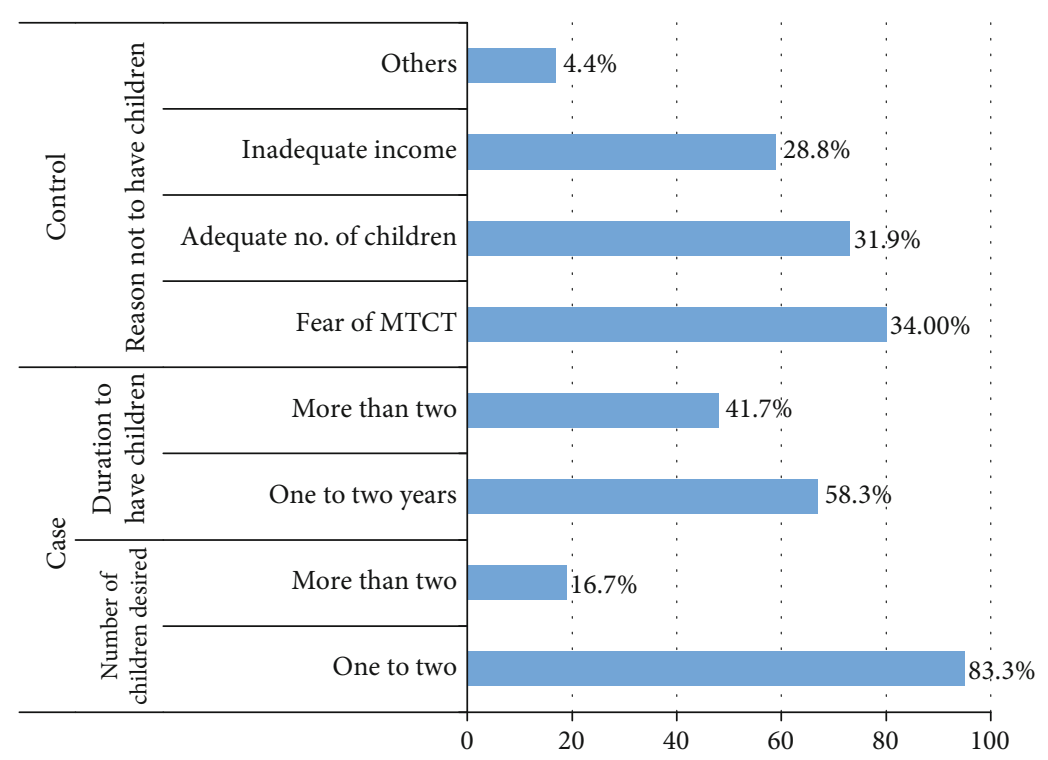

Figure 1: Fertility desire, number, and duration to have children among cases and reasons not to have children among controls of women living with HIV attending ART in Jimma University Medical Center, $2019(N=344)$.

TABLE 2: Bivariate analysis reproductive characteristics of women living with HIV attending ART in Jimma University Medical Center, 2019 $(N=344)$.

\begin{tabular}{|c|c|c|c|c|c|}
\hline Variables & Category & $\begin{array}{c}\text { Cases }(n=115) \\
\text { No. }(\%)\end{array}$ & $\begin{array}{c}\text { Controls }(n=229) \\
\text { No. }(\%)\end{array}$ & COR $(95 \%$ CI $)$ & $P$ values \\
\hline \multirow{2}{*}{ Sexually active } & Yes & $86(76.1)$ & $139(61.2)$ & $2.0(1.2-3.3)$ & $0.007^{*}$ \\
\hline & No & $27(24.0)$ & $88(38.8)$ & 1 & \\
\hline \multirow{2}{*}{ Sexual partner } & Yes & $81(71.7)$ & $110(48.5)$ & $2.7(1.7-4.4)$ & $0.001^{*}$ \\
\hline & No & $32(28.3)$ & $117(51.5)$ & & \\
\hline \multirow{2}{*}{ HIV disclosure } & Yes & $63(77.8)$ & $83(75.5)$ & $1.1(0.6-2.2)$ & 0.709 \\
\hline & No & $18(22.2)$ & $27(24.5)$ & 1 & \\
\hline \multirow{2}{*}{ Partner fertility desire } & Yes & $57(70.4)$ & $77(70.0)$ & $1.0(0.5-1.9)$ & 0.956 \\
\hline & No & $24(29.6)$ & $33(30.0)$ & 1 & \\
\hline \multirow{2}{*}{ Children } & Yes & $65(57.5)$ & $175(77.1)$ & 1 & \\
\hline & No & $48(42.5)$ & $52(22.9)$ & $2.5(1.5-4.0)$ & $0.001^{*}$ \\
\hline \multirow{2}{*}{ History of abortion } & Yes & $24(21.2)$ & $66(29.1)$ & 1 & \\
\hline & No & $89(78.8)$ & $161(70.9)$ & $1.5(0.9-2.6)$ & $0.124^{*}$ \\
\hline \multirow{2}{*}{ Family planning } & Yes & $31(27.4)$ & $126(55.5)$ & 1 & \\
\hline & No & $82(72.6)$ & $101(44.5)$ & $3.3(2.0-5.4)$ & $0.001^{*}$ \\
\hline \multirow{2}{*}{ Family support } & Yes & $82(71.3)$ & $126(55.0)$ & $2.0(1.3-3.3)$ & $0.004^{*}$ \\
\hline & No & $33(28.7)$ & $103(45.0)$ & 1 & \\
\hline \multirow{2}{*}{ Pressure from family to have children } & Yes & $57(49.6)$ & $77(33.6)$ & $1.9(1.2-3.0)$ & $0.004^{*}$ \\
\hline & No & $58(50.4)$ & $152(66.4)$ & 1 & \\
\hline \multirow{2}{*}{ Discussion with heath professional } & Yes & $83(72.2)$ & $161(70.3)$ & $1.1(0.7-1.8)$ & 0.719 \\
\hline & No & $32(27.8)$ & $68(29.7)$ & 1 & \\
\hline \multirow{2}{*}{ History of sexual violence } & Yes & $40(34.8)$ & $52(22.7)$ & $1.8(1.1-3.0)$ & $0.018^{*}$ \\
\hline & No & $75(65.2)$ & $173(73.3)$ & 1 & \\
\hline
\end{tabular}

Key: $*=P$ value $<0.25 ; 1=$ reference category.

planning, family support, family pressure to have children, and history of sexual violence were potential candidates for multiple logistic regression (see Table 2).
3.3. Pregnancy-Related Knowledge among Women on FollowUp of ART. This study also assessed pregnancy-related knowledge of women attending ART. All cases and controls 
TABLE 3: Assessments of HIV pregnancy-related knowledge among women living with HIV attending ART at Jimma University Medical Center, $2019(N=344)$.

\begin{tabular}{|c|c|c|c|c|}
\hline Variables & Category & & $\begin{array}{c}\text { Cases }(n=115) \\
\text { No. }(\%)\end{array}$ & $\begin{array}{c}\text { Cases }(n=115) \\
\text { No. }(\%)\end{array}$ \\
\hline \multirow{6}{*}{ HIV transmission } & \multirow{2}{*}{ Common use of sharp material } & Yes & $108(93.4)$ & $211(92.1)$ \\
\hline & & No & $7(6.1)$ & $18(7.9)$ \\
\hline & \multirow{2}{*}{ Unsafe sex } & Yes & $111(96.5)$ & $213(93.0)$ \\
\hline & & No & $4(3.5)$ & $16(7.0)$ \\
\hline & \multirow{2}{*}{ Blood transfusion } & Yes & $35(30.4)$ & $56(24.5)$ \\
\hline & & No & $80(69.6)$ & $173(75.5)$ \\
\hline \multirow{6}{*}{ HIV prevention } & \multirow{2}{*}{ Faithful } & Yes & $62(53.9)$ & $147(64.2)$ \\
\hline & & No & $53(46.1)$ & $82(36.0)$ \\
\hline & \multirow{2}{*}{ Abstinence } & Yes & $91(79.1)$ & $182(79.5)$ \\
\hline & & No & $24(20.9)$ & $47(20.6)$ \\
\hline & \multirow{2}{*}{ Safe sexual practice } & Yes & $73(63.5)$ & $143(63.2)$ \\
\hline & & No & $42(36.5)$ & $126(36.8)$ \\
\hline \multirow{6}{*}{ MTCT of HIV } & \multirow{2}{*}{ During pregnancy } & Yes & $72(63.7)$ & $158(69.6)$ \\
\hline & & No & $41(36.3)$ & $69(30.4)$ \\
\hline & \multirow{2}{*}{ Labor and delivery } & Yes & $64(56.6)$ & $145(63.9)$ \\
\hline & & No & $49(43.4)$ & $82(36.1)$ \\
\hline & \multirow{2}{*}{ Breastfeeding } & Yes & $91(80.5)$ & $179(78.9)$ \\
\hline & & No & $22(19.5)$ & $48(21.1)$ \\
\hline \multirow{4}{*}{ PMTCT of HIV } & \multirow{2}{*}{ ART medication } & Yes & $89(96.7)$ & $197(97.0)$ \\
\hline & & No & $3(3.3)$ & $6(3.0)$ \\
\hline & \multirow{2}{*}{ Condom use } & Yes & $20(22.0)$ & $23(11.4)$ \\
\hline & & No & $71(78.0)$ & $179(88.9)$ \\
\hline \multirow{6}{*}{ Infant feeding option } & \multirow{2}{*}{ Infant formula, no breast milk } & Yes & $23(24.0)$ & 63 (29.9) \\
\hline & & No & $73(76.0)$ & $148(70.1)$ \\
\hline & \multirow{2}{*}{ Cow’s milk, no breast milk } & Yes & $16(16.7)$ & $38(18.0)$ \\
\hline & & No & $80(83.3)$ & $173(82.0)$ \\
\hline & \multirow{2}{*}{ Breast milk only for six months } & Yes & $74(77.1)$ & $170(80.6)$ \\
\hline & & No & $22(22.9)$ & $41(19.4)$ \\
\hline
\end{tabular}

mentioned at least one way of HIV transmission and prevention. Almost all respondent $111(96.5 \%)$ of the cases and 213 (93.0\%) of the controls mentioned unsafe sex as a mode of HIV transmission. About 91 (80.5\%) cases and 179 (78.9\%) controls mentioned that HIV can be transmitted through breastfeeding. More than majority 89 (96.7\%) of the cases and $197(97.0 \%)$ of the controls mentioned through ART medication (see Table 3).

3.4. Clinical Characteristics. Majority of the cases 102 (88.7\%) and controls 195 (85.2\%) were tested for HIV before a year of the study. Almost a similar proportion of cases $102(88.7 \%)$ and controls 194 (84.7\%) were on ART for more than one year. Concerning their CD4 count, more than three-fourth of $90(78.3 \%)$ cases and $158(69.0 \%)$ controls had CD4 $\geq$ 350. Majority of $78(67.8 \%)$ cases and half of $131(51.7 \%)$ controls have their viral load cannot be detected (TND). About half $59(51.3 \%)$ of the cases had poor knowledge whereas closely two-third 148 (64.6\%) of the controls had good knowledge of HIV transmission and prevention.
In bivariate analysis from all clinical characteristics, CD4 count, viral load, and knowledge were potential candidates for multiple logistic regression (see Table 4).

3.5. Determinants of Fertility Desire. From the total variable entered in the multivariable regression, three variables were found to be independently associated with fertility desire among women living with HIV (see Table 5). The odds of fertility desire among the age group 15-24 years and 25-34 were four times (AOR: 4.1; 95\% CI: 2.0, 8.4) and two times (AOR: 2.3; $95 \% \mathrm{CI}: 1.3,4.2)$ higher as compared to age range from 35 to 49 years, respectively.

The odds of fertility desire among women who had not used family planning were two times (AOR: 2.3 ; 95\% CI: $1.4,4.0$ ) higher as compared to those women living with HIV who use family planning. The odds of fertility desire among women who had sexual partners were about two times (AOR: 1.9; 95\% CI: 1.1-3.2) higher when compared to those women living with HIV who had no sexual partners (see Table 5). 
TABLE 4: Bivariate analysis of clinical characteristics of women living with HIV attending ART in Jimma University Medical Center, 2019 $(N=344)$.

\begin{tabular}{|c|c|c|c|c|c|}
\hline Variables & Category & $\begin{array}{c}\text { Cases }(n=115) \\
\text { No. }(\%)\end{array}$ & $\begin{array}{c}\text { Controls } \\
(n=229) \\
\text { No. }(\%)\end{array}$ & COR $(95 \% \mathrm{CI})$ & $P$ values \\
\hline \multirow{2}{*}{ Tested time of HIV } & $<1$ year & $13(11.3)$ & $34(14.8)$ & $0.7(0.4-1.4)$ & 0.368 \\
\hline & $\geq 1$ year & $102(88.7)$ & $195(85.7)$ & 1 & \\
\hline \multirow{2}{*}{ Started time of ART } & $<1$ year & $13(11.3)$ & $35(15.3)$ & $0.7(0.3-1.4)$ & 0.317 \\
\hline & $\geq 1$ year & $102(88.7)$ & $194(84.7)$ & 1 & \\
\hline \multirow{2}{*}{ CD4 count } & $<350$ & $25(21.7)$ & $71(31.0)$ & 1 & \\
\hline & $\geq 350$ & $90(78.3)$ & $158(69.0)$ & $1.6(0.9-2.7)$ & $0.072^{*}$ \\
\hline \multirow{3}{*}{ Viral load } & TND & $78(67.8)$ & $131(57.2)$ & $1.6(0.9-3.1)$ & $0.129^{*}$ \\
\hline & $<20$ & $21(18.3)$ & $54(23.6)$ & $1.1(0.5-2.3)$ & 0.863 \\
\hline & $>20$ & $16(13.9)$ & $44(19.2)$ & 1 & \\
\hline \multirow{2}{*}{ Partner tested for HIV } & Yes & $64(79.0)$ & $81(73.6)$ & 1 & \\
\hline & No & $17(21)$ & $29(25.4)$ & $0.7(0.4-1.5)$ & 0.391 \\
\hline \multirow{2}{*}{ Partner HIV status } & Positive & $47(73.6)$ & $54(66.7)$ & 1 & \\
\hline & Negative & $17(26.4)$ & $27(33.3)$ & $0.7(0.3-1.5)$ & 0.379 \\
\hline \multirow{2}{*}{ Health status } & Improving & $105(91.3)$ & $202(88.2)$ & 1 & \\
\hline & Same & $10(8.7)$ & $27(11.8)$ & $0.7(0.3-1.5)$ & 0.384 \\
\hline \multirow{2}{*}{ Discrimination by health professionals } & Yes & $12(10.4)$ & $19(8.3)$ & $1.2(0.6-2.7)$ & 0.514 \\
\hline & No & $103(89.6)$ & $210(91.7)$ & 1 & \\
\hline \multirow{2}{*}{ Knowledge } & Poor & $59(51.3)$ & $81(35.4)$ & $1.9(1.2-3.0)$ & $0.005^{*}$ \\
\hline & Good & $56(48.7)$ & $148(64.6)$ & 1 & \\
\hline
\end{tabular}

Key: $*=P$ value $<0.25 ; 1=$ reference category; $\mathrm{TND}=$ target not detected.

\section{Discussion}

Understanding the desire for fertility among women living with HIV/AIDS has a significant role to reduce MTCT of HIV with the introduction of ART, which changes the views of childbearing despite having the disease [31].

Age of the women was significantly associated with fertility desire. Women of younger age had higher odds fertility desire as compared to older women. This finding is similar to that of studies from Brazil, Canada, USA, Guinea, Ghana, and Rwanda which indicate that young women living with HIV experience significantly more fertility desire than HIVinfected, older women [7, 13, 15-17, 25]. In Ethiopia, some studies demonstrated the presence of an association between age and fertility desire $[10,12,20]$. The possible similarity is that it is quite normal to have a fertility desire during this period $b / c$ it is the peak of reproduction. In many societies, women are active in producing their offsprings during this period [32]. On the contrary in another study, being young was reported to be inversely associated with fertility desire [33]. The possible reason for the inconsistency may be sociocultural or methodological differences between study participants.

In the current study, the odds of fertility desire among women, who had not used family planning, were higher when compared with those who used family planning. This finding is supported by a study done in Uganda and Guinea $[25,34]$, which revealed that women who have not used any family planning are more likely to have fertility desire than those who used. A study in Ethiopia has reported the same finding [35]. This might be due to the fact that they have not attained their desired family size and unmet need of family planning service [36]. In contrast, having no family planning is negatively associated with fertility desire [37]. The possible difference might be due to poor economic status having less fertility desire. The health workers providing their chronic AIDS care must be made aware of this, and a range of contraceptive options should be made available, as well as all the associated information about these options.

Women who had sexual partners had higher odds of fertility desire as compared to women who had no sexual partners. This result is also in line with the study done in Tanzania and Guinea $[23,25]$ which stated that odds of fertility desire were high on women who had sexual partners than their counterparts. A study in Ethiopia reported the same finding [20]. Probably, this may be due to the fact that having sexual partners may play a role in preconception planning behaviors. Moreover, having male partners minimizes her economic, social, and psychological burden of HIV/AIDS [12]. Thus, policymakers and health care providers should consider the role of male partners while developing policy and running an HIV/AIDS intervention.

4.1. Study Limitation. Men were not included in the study, in spite of the essential role they can play in deciding about their family size. This study is also limited to women who are receiving chronic, long-term care for their HIV infection, despite fertility desire differing from women who are not 
TABLE 5: Multivariable analysis of factors associated with fertility desire among women living with HIV attending ART in Jimma University Medical Center, $2019(N=344)$.

\begin{tabular}{|c|c|c|c|c|c|c|}
\hline Variables & Category & $\begin{array}{c}\text { Cases }(n=115) \\
\text { No. }(\%)\end{array}$ & $\begin{array}{c}\text { Controls }(n=229) \\
\text { No. }(\%)\end{array}$ & COR $(95 \% \mathrm{CI})$ & AOR (95\% CI) & $P$ values \\
\hline \multirow{3}{*}{ Age } & $15-24$ & $38(33.1)$ & $31(13.5)$ & $5.9(3.0-11.4)$ & $4.1(2.0-8.4)$ & $<0.001^{* *}$ \\
\hline & $25-34$ & $55(47.8)$ & $92(40.2)$ & $2.9(1.6-5.1)$ & $2.3(1.3-4.2)$ & $0.005^{* *}$ \\
\hline & $35-49$ & $22(19.1)$ & $106(46.3)$ & 1 & 1 & \\
\hline \multirow{3}{*}{ Household wealth index } & Poor & $43(37.4)$ & $71(31.0)$ & 1 & 1 & \\
\hline & Medium & $33(28.6)$ & $84(36.7)$ & $0.6(0.4-1.1)$ & $0.7(0.4-1.2)$ & 0.206 \\
\hline & Good & 39 (33.9) & $74(32.3)$ & $0.9(0.5-1.5)$ & $0.9(0.5-1.6)$ & 0.715 \\
\hline \multirow{2}{*}{ History of sexual violence } & Yes & $40(34.8)$ & $52(22.7)$ & $1.8(1.1-3.0)$ & $0.9(0.4-1.6)$ & 0.764 \\
\hline & No & $75(65.2)$ & $173(73.3)$ & 1 & 1 & \\
\hline \multirow{2}{*}{ Family support } & Yes & $82(71.3)$ & $126(55.0)$ & $2.0(1.3-3.3)$ & $1.0(0.5-2.0)$ & 0.913 \\
\hline & No & $33(28.7)$ & $103(45.0)$ & 1 & 1 & \\
\hline \multirow{2}{*}{ Pressure from family to have children } & Yes & $57(49.6)$ & $77(33.6)$ & $1.9(1.2-3.0)$ & $0.8(0.4-1.6)$ & 0.588 \\
\hline & No & $58(50.4)$ & $152(66.4)$ & 1 & 1 & \\
\hline \multirow{2}{*}{ Sexually active } & Yes & $86(76.0)$ & $139(61.2)$ & $2.0(1.2-3.3)$ & $0.8(0.3-1.9)$ & 0.629 \\
\hline & No & $27(24.0)$ & $88(38.8)$ & 1 & 1 & \\
\hline \multirow{2}{*}{ Sexual partner currently } & Yes & $81(71.7)$ & $110(48.5)$ & $2.7(1.7-4.4)$ & $1.9(1.1-3.2)$ & $0.015^{* *}$ \\
\hline & No & $32(28.3)$ & $117(51.5)$ & 1 & 1 & \\
\hline \multirow{3}{*}{ Viral load } & TND & $78(67.8)$ & $131(57.2)$ & $1.6(0.9-3.1)$ & $1.3(0.6-2.7)$ & 0.498 \\
\hline & $<20$ & $21(18.3)$ & $54(23.6)$ & $1.1(0.5-2.3)$ & $1.1(0.4-2.5)$ & 0.875 \\
\hline & $>20$ & $16(13.9)$ & $44(19.2)$ & 1 & 1 & \\
\hline \multirow{2}{*}{ CD4 count } & $<350$ & $25(21.7)$ & $71(31.0)$ & 1 & 1 & \\
\hline & $\geq 350$ & $90(78.3)$ & $158(69.0)$ & $1.6(0.9-2.7)$ & $1.6(0.9-2.9)$ & 0.093 \\
\hline \multirow{2}{*}{ Children } & Yes & $65(57.5)$ & $175(77.1)$ & 1 & 1 & \\
\hline & No & $48(42.5)$ & $52(22.9)$ & $2.5(1.5-4.0)$ & $0.7(0.3-1.3)$ & 0.237 \\
\hline \multirow{2}{*}{ Family planning } & Yes & $31(27.4)$ & $126(55.5)$ & 1 & 1 & \\
\hline & No & $82(72.6)$ & $101(44.5)$ & $3.3(2.0-5.4)$ & $2.3(1.4-4.0)$ & $0.001^{* *}$ \\
\hline \multirow{2}{*}{ History of abortion } & Yes & $24(21.2)$ & $66(29.1)$ & 1 & 1 & \\
\hline & No & $89(78.8)$ & $161(70.9)$ & $1.5(0.9-2.6)$ & $0.7(0.4-1.4)$ & 0.433 \\
\hline \multirow{2}{*}{ HIV pregnancy-related knowledge } & Poor & $59(51.3)$ & $81(35.4)$ & $1.9(1.2-3.0)$ & $0.8(0.4-1.5)$ & 0.521 \\
\hline & Good & $56(48.7)$ & $148(64.6)$ & 1 & 1 & \\
\hline
\end{tabular}

Key: $* *=P$ value $<0.05 ; 1=$ reference category; $\mathrm{TND}=$ target not detected.

receiving the care. Furthermore, this study included secondary school girls; most of them are not sexually active and may not want to have children shortly, and this may bias the findings of this study.

4.2. Conclusions and Recommendation. This study revealed that age of the women, family planning, and permanent sexual partner were the independent determinants of fertility desire among women living with HIV attending ART at JUMC. This finding has an implication for the health care provider and policymakers to consider the effects of these variables while discussing the reproductive option, family planning service, and safer conception; providing adequate information about PMTCT of HIV; and assisting them in making informed reproductive decision to minimize the risk of MTCT of HIV and unplanned pregnancy. Further studies including men and qualitative methods can help deepen understanding of fertility desire among women living with
HIV on ART follow-up. Moreover, previous studies revealed that age is a known confounder of fertility desire, so we have recommended further studies with age-matched case-control analysis to control the effects of age.

\section{Abbreviations}

AIDS: Acquired immune deficiency syndrome

AOR: Adjusted odds ratio

ART: Antiretroviral therapy

COR: Crude odds ratio

EDHS: Ethiopia Demographic and Health Survey

HIV: Human immunodeficiency virus

JUMC: Jimma University Medical Center

MTCT: Mother-to-child transmission

PLWHA: People living with HIV/AIDS

PMTCT: Preventing mother-to-child transmission

TND: $\quad$ Target not detected 
UNAID: United Nations Program on HIV/AIDS

WHO: World Health Organization.

\section{Data Availability}

The dataset generated and analyzed during the study will be made available to organizations and individuals based on reasonable request.

\section{Conflicts of Interest}

The authors declare that they do not have competing interests.

\section{Authors' Contributions}

NSA was involved in the conception and design of the study, data acquisition, data processing, analysis, and drafting of the manuscript. LSD was involved in designing, data analysis, and substantial revision of the manuscript. EA participated in designing, data analysis, and interpreting the results. MAM was involved in data collection, data entry, and data analysis.

\section{Acknowledgments}

The authors are grateful to Jimma University for financial support to conduct this study. Special thanks also go to Jimma University Medical Center ART clinic staffs for providing pertinent information regarding patients on ART follow-up. Finally, the author would like to acknowledge research assistants and study participants for their cooperation. The study was funded by Jimma University.

\section{References}

[1] UNAIDS, "UNAIDS data," http://www.unaids.org/sites/ default/files/media_asset/20170720_Data_book_2017_en.pdf.

[2] Federal Democratic Republic of Ethiopia-Ministry of Health, Demographic health survey H. Ethiopia, Central Statistical Agency/CSA/Ethiopia, Addis Abeba, 2016.

[3] WHO, "Mother-to-child transmission of HIV," http://www .who.int/hiv/topics/mtct/en/.

[4] Aert (Global information and education on HIV and AIDS, Global information and education on HIV and AIDS Avert, Avert (HIV and AIDS organization), 2018.

[5] G. M. Kassa, "Mother-to-child transmission of HIV infection and its associated factors in Ethiopia: a systematic review and meta-analysis," BMC Infectious Diseases, vol. 18, no. 1, 2018.

[6] Ethiopian public health institute, HIV related estimates and projections for Ethiopia - 2017, EPHI (Ethiopian Public Health Institute), 2017.

[7] M. R. Loutfy, T. A. Hart, S. S. Mohammed et al., "Fertility desires and intentions of HIV-positive women of reproductive age in Ontario, Canada: a cross-sectional study," PLoS One, vol. 4, no. 12, article e7925, 2009.

[8] J. W. Krashin, L. B. Haddad, H. Tweya et al., "Factors associated with desired fertility among HIV-positive women and men attending two urban clinics in Lilongwe, Malawi," vol. 13, no. 6, Article ID e0198798, 2018.
[9] A. S. Melka, M. A. Wordofa, and B. A. Wossen, "Determinants of fertility intention among women living with HIV in Western Ethiopia: implications for service delivery," African Journal of Reproductive Health, vol. 18, no. 4, pp. 54-60, 2014.

[10] F. Mohammed and N. Assefa, "Determinants of desire for children among HIV-positive women in the Afar region, Ethiopia : case control study," PLoS One, vol. 11, no. 3, article e0150566, 2016.

[11] T. Menna and H. Wordofa, "Prevalence of fertility desire and its associated factors among 15- to 49-year-old people living with HIV / AIDS in Addis Ababa, Ethiopia: a cross-sectional study design," HIVIAIDS - Research and Palliative Care, vol. 9, pp. 167-176, 2017.

[12] Y. A. Melaku, E. G. Zeleke, J. Kinsman, and A. K. Abraha, "Fertility desire among HIV-positive women in Tigray region, Ethiopia: implications for the provision of reproductive health and prevention of mother-to-child HIV transmission services," BMC Women's Health, vol. 14, no. 1, p. 137, 2014.

[13] M. R. de Souza, W. N. do Amaral, R. A. Guimarães, G. Rezza, and S. M. Brunini, "Reproductive desire among women living with HIV / AIDS in Central Brazil: prevalence and associated factors," PLoS One, vol. 12, no. 10, article e0186267, 2017.

[14] C. Nöstlinger, F. Desjardins, J. Dec, T. Platteau, E. Hasker, and the Eurosupport V Study Group, "Child desire in women and men living with HIV attending HIV outpatient clinics: evidence from a European multicentre study," The European Journal of Contraception \& Reproductive Health Care, vol. 18, no. 4, pp. 251-263, 2013.

[15] D. L. Jones, R. Cook, J. N. E. Potter et al., "Fertility desires among women living with HIV," PLoS One, vol. 11, no. 9, article e0160190, 2016.

[16] E. Remera, K. Boer, S. M. Umuhoza et al., "Fertility and HIV following universal access to ART in Rwanda: a crosssectional analysis of Demographic and Health Survey data," Reproductive Health, vol. 14, no. 1, p. 40, 2017.

[17] A. A. Gyimah, E. K. Nakua, and E. O. E. Owusu-Dabo, "Fertility preferences of women living with HIV in the Kumasi Metropolis, Ghana," African Journal of Reproductive Health, vol. 19, no. 2, pp. 124-132, 2015.

[18] J. Kimani, on behalf of the Integra Initiative, C. Warren et al., "Family planning use and fertility desires among women living with HIV in Kenya," BMC Public Health, vol. 15, no. 1, p. 909, 2015.

[19] L. J. Nakiganda, A. Agardh, and B. O. Asamoah, "Cross-sectional study on the prevalence and predictors of pregnancy among women living in HIV discordant relationships in a rural Rakai cohort, Uganda," BMJ Open, vol. 8, no. 4, article e019818, 2018.

[20] H. M. Asfaw and F. E. Gashe, "Fertility intentions among HIV positive women aged 18 - 49 years in Addis Ababa Ethiopia: a cross sectional study," Reproductive Health, vol. 11, no. 1, p. 36, 2014.

[21] A. O. Ashimi, T. G. Amole, M. Y. Abubakar, and E. A. Ugwa, "Fertility desire and utilization of family planning methods among HIV-positive women attending a tertiary hospital in a suburban setting in Northern Nigeria," Tropical Journal of Obstetrics and Gynaecology, vol. 34, no. 1, p. 54, 2017.

[22] H. Mekonnen and F. Enquselassie, "Effect of antiretroviral therapy on changes in the fertility intentions of human immunodeficiency virus-positive women in Addis Ababa, Ethiopia: a prospective follow-up study," Epidemiology and Health, vol. 39, article e2017028, 2017. 
[23] E. J. Mmbaga, G. H. Leyna, M. J. Ezekiel, and D. C. Kakoko, "Fertility desire and intention of people living with HIV / AIDS in Tanzania: a call for restructuring care and treatment services," BMC Public Health, vol. 13, no. 1, p. 86, 2013.

[24] J. L. Finger, G. A. Clum, M. E. Trent, J. M. Ellen, and the Adolescent Medicine, "Desire for pregnancy and risk behavior in young HIV-Positive Women," AIDS Patient Care and STDs, vol. 26, no. 3, pp. 173-180, 2012.

[25] M. L. Aska, J. Chompikul, and B. Keiwkarnka, "Determinants of fertility desires among HIV positive women living in the Western Highlands Province of Papua New Guinea," World Journal of AIDS, vol. 1, no. 4, pp. 198-207, 2011.

[26] Federal Democratic Republic of Ethiopia-Ministry of Health, Demographic and Health Survey(EDHS), Central Statistical Agency/CSA/Ethiopia, Ethiopia, 2016.

[27] T. Regassa and M. Fantahun, "Fertility Desire and Reproductive Health Care Needs of Men and Women Living with HIV/AIDS in Nekemte, East Wollega, Ethiopia," Science, Technology and Arts Research Journal, vol. 1, no. 3, p. 31, 2013.

[28] M. C. Transmission and A. Care, "Clinics in mother and child health ment of knowledge and attitude towards prevention of $\mathrm{M}$ ransmission of HIV / AIDS among antenatal care client in own public health facilities, Benchi-Maji Zone, South Na lities and People Region, Southwest Ethiopia," Clinics in Mother and Child Health, vol. 2020, pp. 1-14, 2017.

[29] WHO, "Sexual violence," A companion to crime, harm and victimisation, Policy Press, 2016.

[30] M. den Oudsten, J. van Kampen, B. Rijnders, D. van de Vijver, and M. van der Ende, "Is HIV-1 viraemia below 20 copies / mL in antiretroviral-treated patients associated with virologic outcome?," Infectious Diseases, vol. 51, no. 4, pp. 259-267, 2019.

[31] M. A. Magadi and A. O. Agwanda, "Investigating the association between HIV/AIDS and recent fertility patterns in Kenya," Social Science \& Medicine, vol. 71, no. 2, pp. 335344, 2010.

[32] Central Statistical Agency, "Ethiopia Demograhic Health Survey(EDHS)," 2016, http://www.dhsprogram.com/pubs/pdf/ FR118/FR118.pdf.

[33] O. Kakaire, M. O. Osinde, and D. K. Kaye, "Factors that predict fertility desires for people living with HIV infection at a support and treatment centre in Kabale, Uganda," Reproductive Health, vol. 7, no. 1, p. 27, 2010.

[34] J. K. B. Matovu, F. Makumbi, R. K. Wanyenze, and D. Serwadda, "Determinants of fertility desire among married or cohabiting individuals in Rakai, Uganda: a cross-sectional study," Reproductive Health, vol. 14, no. 1, p. 2, 2017.

[35] I. Harari, R. State, F. Haile, N. Isahak, and A. Dessie, "Fertility desire and associated factors among people living with HIV on ART, In Harari Regional State, Eastern Ethiopia," Journal of Tropical Diseases, vol. 2, no. 3, pp. 2-7, 2014.

[36] D. O. Laryea, Y. A. Amoako, K. Spangenberg, E. Frimpong, and J. Kyei-Ansong, "Contraceptive use and unmet need for family planning among HIV positive women on antiretroviral therapy in Kumasi Ghana," BMC Women's Health, vol. 14, no. 1, p. 126, 2014.

[37] F. Abbawa, W. Awoke, and Y. Alemu, "Fertility desire and associated factors among clients on highly active antiretroviral treatment at finoteselam hospital Northwest Ethiopia : a cross sectional study," Reproductive Health, vol. 12, p. 69, 2015. 